J. Dairy Sci. 95:2381-2389

http://dx.doi.org/10.3168/jds.2011-4450

(C) American Dairy Science Association ${ }^{\circledR}, 2012$.

\title{
Endogenous and exogenous progesterone influence body temperature in dairy cows
}

\author{
V. S. Suthar, ${ }^{*}$ O. Burfeind, ${ }^{*}$ S. Bonk, ${ }^{*}$ A. J. Dhami, $†$ and W. Heuwieser ${ }^{\star 1}$ \\ ${ }^{*}$ Clinic of Animal Reproduction, Faculty of Veterinary Medicine, Freie Universität Berlin, Koenigsweg 65, 14163 Berlin, Germany \\ †Department of Animal Reproduction, Gynaecology and Obstetrics, College of Veterinary Science, Anand Agricultural University, \\ Anand-388110, Gujarat, India
}

\section{ABSTRACT}

Three experiments were conducted to determine the effect of endogenous progesterone (P4) on body temperature comparing lactating, pregnant with lactating, nonpregnant cows, and to study the effect of exogenous $\mathrm{P} 4$ administered via a controlled internal drug release (CIDR) insert on body temperature in lactating dairy cows. Body temperature was measured vaginally and rectally using temperature loggers and a digital thermometer, respectively. In experiment 1, 10 cyclic lactating cows ( 3 primiparous, 7 multiparous) and 10 lactating, pregnant cows (3 primiparous, 7 multiparous) were included. Vaginal temperatures and serum $\mathrm{P} 4$ concentrations were greater in pregnant cows (vaginal: $0.3 \pm 0.01^{\circ} \mathrm{C}$; P4: $5.5 \pm 0.4 \mathrm{ng} / \mathrm{mL}$ ) compared with nonpregnant cows. In experiment 2 , estrous cycles of 14 postpartum healthy, cyclic, lactating cows (10 primiparous, 4 multiparous) were synchronized, and cows were assigned randomly to 1 of 2 treatments (CIDR-P4 or CIDR-blank). A temperature logger was inserted 1 $\mathrm{d}$ after ovulation using a P4-free CIDR (CIDR-blank) and a CIDR containing $1.38 \mathrm{~g}$ of P4 (CIDR-P4) in the control $(\mathrm{n}=7)$ and the P4-treated group $(\mathrm{n}=7)$, respectively. On d 3 after $\mathrm{P} 4$ treatment, vaginal temperature was $0.3 \pm 0.03^{\circ} \mathrm{C}$ greater compared with that on $\mathrm{d}$ 1 and $\mathrm{d} 5$. In experiment 3, 9 cyclic multiparous lactating cows were enrolled $1 \pm 1 \mathrm{~d}$ after confirmed ovulation and a temperature logger inserted. Two days later, a CIDR-P4 was inserted on top of the CIDR-blank. On $\mathrm{d} 5 \pm 1$ and $\mathrm{d} 7 \pm 1$, respectively, the CIDR-P4 and CIDR-blank with the temperature logger were removed. During the CIDR-P4 treatment $(48 \mathrm{~h})$, vaginal temperature was $0.2 \pm 0.05^{\circ} \mathrm{C}$ and $0.1 \pm 0.05^{\circ} \mathrm{C}$ greater than during the pre- and post-treatment periods (48 h), respectively. Serum P4 concentration peaked during CIDR-P4 treatment $(2.2 \pm 0.8 \mathrm{ng} / \mathrm{mL})$ and was greater than during the pre-treatment period $(0.2 \pm 0.2 \mathrm{ng} /$

Received April 14, 2011.

Accepted January 10, 2012.

${ }^{1}$ Corresponding author: heuwieser.wolfgang@vetmed.fu-berlin.de
$\mathrm{mL}$ ) for $48 \mathrm{~h}$. An increase in vaginal temperature could be due to endogenous and exogenous P4. However, a correlation between serum P4 concentrations and body temperature did not exist. Further investigations are warranted to better understand the pathways of the thermogenic effect of $\mathrm{P} 4$ on body temperature.

Key words: dairy cow, progesterone, body temperature

\section{INTRODUCTION}

Evidence indicates that fluctuations in body temperature (BT) are associated with changes in plasma progesterone (P4) concentration in pregnant and cyclic dairy cattle (Wrenn et al., 1958, 1961; Kyle et al., 1998). Several studies demonstrated greater BT during pregnancy (Wrenn et al., 1958; Kendall and Webster, 2009) and a subsequent decrease $\left(\geq 1^{\circ} \mathrm{C}\right)$ within 16 to $48 \mathrm{~h}$ before spontaneous (Birgel et al., 1994; Lammoglia et al., 1997; Burfeind and Heuwieser, 2011) or induced (Kornmatitsuk et al., 2000) parturition in dairy cows. Both BT and P4 have been valuable predictors for parturition (Birgel et al., 1994). Most recently, Burfeind et al. (2011) determined test characteristics of a prepartum decrease in BT (rectal and vaginal temperature) for predicting parturition in dairy cows $(\mathrm{n}=85)$. A decrease of vaginal temperature $\geq 0.3^{\circ} \mathrm{C}$ predicted calving within $24 \mathrm{~h}$, with sensitivity ranging from 62 to $71 \%$ and specificity ranging from 81 to $87 \%$ in primiparous $(\mathrm{n}=30)$ and multiparous $(\mathrm{n}=55)$ dairy cows.

A relationship between the prepartum BT decrease and the decrease in prepartum $\mathrm{P} 4$ has been assumed for decades (Wrenn et al., 1961) and was postulated again recently (Cooper-Prado et al., 2011). A correlation between $\mathrm{BT}$ and $\mathrm{P} 4$ concentrations has not been demonstrated (Lammoglia et al., 1997; Suthar et al., 2011).

To our knowledge, only 1 study (Wrenn et al., 1959) demonstrated an effect of $\mathrm{P} 4$ administered s.c. on BT in dairy cows with a maximum increase occurring on d 2 after treatment. In total, 11 individual trials were performed on 4 ovariectomized cows. Progesterone was administered as a single $(250 \mathrm{mg})$ or multiple $(150 \mathrm{mg})$ 
s.c. or i.p. injection. Body temperature was measured with a thermistor probe inserted $21.6 \mathrm{~cm}$ deep into the vagina. The maximum effect of $\mathrm{P} 4$ was observed on $\mathrm{d}$ 2 post-injection. Vaginal temperature was consistently above the pre-treatment mean $\left(38.2^{\circ} \mathrm{C}\right)$ on $\mathrm{d} 3$ and decreased again on $\mathrm{d} 4$. Although exogenous $\mathrm{P} 4$ is widely used to synchronize estrus in dairy cows and heifers (Larson et al., 2006; Ambrose et al., 2008; von Krueger and Heuwieser, 2011), information is lacking on the relationship between exogenous $\mathrm{P} 4$ and $\mathrm{BT}$ in cattle.

Therefore, the overall objective of these experiments was to elucidate the effect of P4 on BT in dairy cows. More specifically, objectives were to (1) determine the effect of endogenous $\mathrm{P} 4$ on BT comparing lactating, pregnant with lactating, nonpregnant cows, and (2) study the effect of exogenous $\mathrm{P} 4$ administered via a controlled internal drug release (CIDR) insert on BT in lactating dairy cows.

\section{MATERIALS AND METHODS}

Thirty-three healthy, cyclic, lactating, nonpregnant $(43.0 \pm 6$ DIM; mean $\pm \mathrm{SD})$ and 10 healthy, pregnant, lactating dairy cows $(278 \pm 30$ DIM; $180 \pm 5 \mathrm{~d}$ pregnant) were included in 3 experiments conducted during October 2010.

All cows were housed in a freestall facility with slatted floors and freestalls equipped with rubber mats. Both nonpregnant and pregnant cows were fed a TMR consisting of $41.9 \%$ concentrate and mineral mix, $31.2 \%$ corn silage, $24.4 \%$ grass silage, and $2.5 \%$ barley straw on a $\mathrm{DM}$ basis $\left(\mathrm{NE}_{\mathrm{L}}=7.03 \mathrm{MJ} / \mathrm{kg}\right.$ of $\left.\mathrm{DM}\right)$ distributed with a conveyer belt system up to 10 times per day. Cows were milked 3 times daily.

Vaginal temperature was monitored with a microprocessor-controlled temperature logger (Minilog 8, Vemco Ltd., Halifax, Canada; size $=92 \mathrm{~mm} \times 20 \mathrm{~mm}$; weight $=40.5 \mathrm{~g}$ ) attached to a $\mathrm{P} 4$-free modified vaginal controlled internal drug release insert (CIDR-blank). The temperature loggers measured vaginal temperature from 0 to $42^{\circ} \mathrm{C}$ with an accuracy of $\pm 0.3^{\circ} \mathrm{C}$ and a resolution of $0.2^{\circ} \mathrm{C}$. This method was validated by Vickers et al. (2010). In all experiments, temperature loggers were initiated to measure vaginal temperature at 10min intervals for the defined duration of the experiment. Rectal temperatures were measured twice daily $(0700 \pm 1 \mathrm{~h}$ and $1700 \pm 1 \mathrm{~h})$ per cow using a digital thermometer with a $7.8-\mathrm{cm}$ probe (VT 1831, Microlife AG, Widnau, Switzerland). The digital thermometer measured vaginal temperature from 34 to $42^{\circ} \mathrm{C}$ with an accuracy of $\pm 0.1^{\circ} \mathrm{C}$ and a resolution of $0.1^{\circ} \mathrm{C}$. To minimize bias, rectal temperature was measured with same thermometer at the same insertion depth.
Ambient temperature and relative humidity within the experimental pen were recorded every 30 min using a Tinytag Plus II logger (Gemini loggers Ltd., Chichester, West Sussex, UK) that was secured on a beam $3 \mathrm{~m}$ above the ground. This logger measured ambient temperature from -25 to $+85^{\circ} \mathrm{C}$ with an accuracy of $\pm 0.3^{\circ} \mathrm{C}$ and a resolution of $0.01^{\circ} \mathrm{C}$, and relative humidity from 0 to $100 \%$ with an accuracy of $\pm 3 \%$ and a resolution of $0.3 \%$.

In all 3 experiments (except pregnant cows in experiment 1), estrous cycles were synchronized by administering $\mathrm{PGF}_{2 \alpha}$ i.m. (Cloprostenol, $0.5 \mathrm{mg}$, PGF Veyx forte, Veyx-Pharma GmbH, Schwarzenborn, Germany) when a corpus luteum $(\mathbf{C L})$ was diagnosed by ultrasound (Tringa Linear, Esaote Piemedical, Maastricht, the Netherlands). This treatment was repeated within $14 \mathrm{~d}$ because some cows did not show signs of estrus. Observation for estrus was performed before milking (i.e., when cows were walking to the milking parlor and in the holding area). Standing estrus and secondary signs (i.e., vaginal discharge, behavior changes) were observed and estrus was later confirmed by transrectal palpation and ultrasonography. Although all 10 pregnant cows in experiment 1 had been diagnosed pregnant between 35 to $42 \mathrm{~d}$ post-insemination by the herd veterinarian, pregnancy status was reconfirmed by transrectal palpation and ultrasonography before enrolling a cow.

Blood samples were obtained by puncture of the coccygeal blood vessel using a vacuum tube system (Venoject II, Terumo Europe N.V., Leuven, Belgium). In all 3 experiments, blood samples were centrifuged (10 min, $1,000 \times g)$ and serum was stored in 2 aliquots at $-20^{\circ} \mathrm{C}$ until analysis. Serum P4 concentrations were analyzed (ng/mL) using a hormonal chemiluminescence assay (Immulite 2000 Siemens, Synlab, Berlin, Germany). The intra- and interassay CV were 5.8 and $10.2 \%$, respectively. As inclusion criteria, serum P4 concentration had to decline to $<1 \mathrm{ng} / \mathrm{mL}$ after the second $\mathrm{PGF}_{2 \alpha}$ treatment and cows had to ovulate within $72 \mathrm{~h}$.

\section{Experiment 1}

In this experiment, 10 lactating, nonpregnant, and cyclic (3 primiparous, 7 multiparous) and 10 lactating, pregnant cows (3 primiparous, 7 multiparous) were included. Nonpregnant cows (40 \pm 5 DIM; $\mathrm{n}=10)$ received a vaginal temperature logger $1 \mathrm{~d}$ after confirmed ovulation for $7 \mathrm{~d}$ consecutively (Figure 1). Pregnant cows $(278 \pm 30$ DIM; $\mathrm{n}=10)$ received a temperature logger at $180 \pm 5 \mathrm{~d}$ after AI. In both groups, vaginal temperatures were measured for $7 \mathrm{~d}$ consecutively using a temperature logger. Blood samples were col- 


\section{Experiment 1}

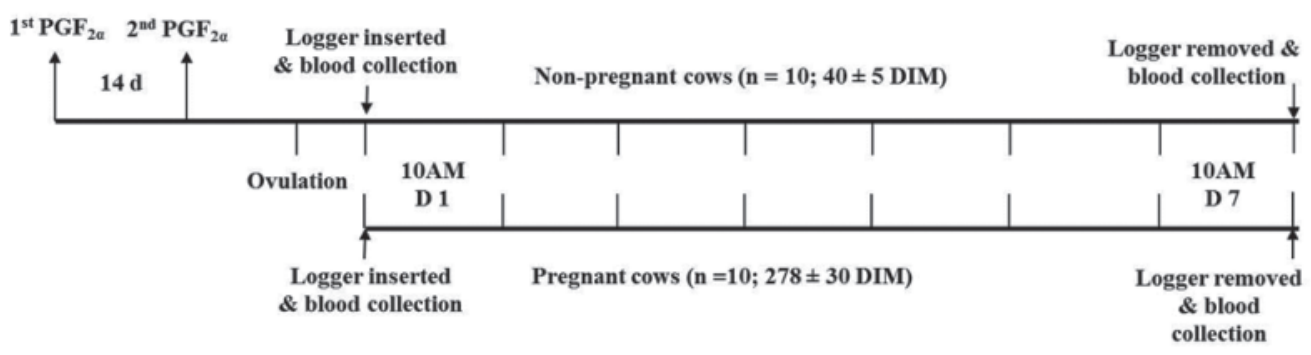

Experiment 2

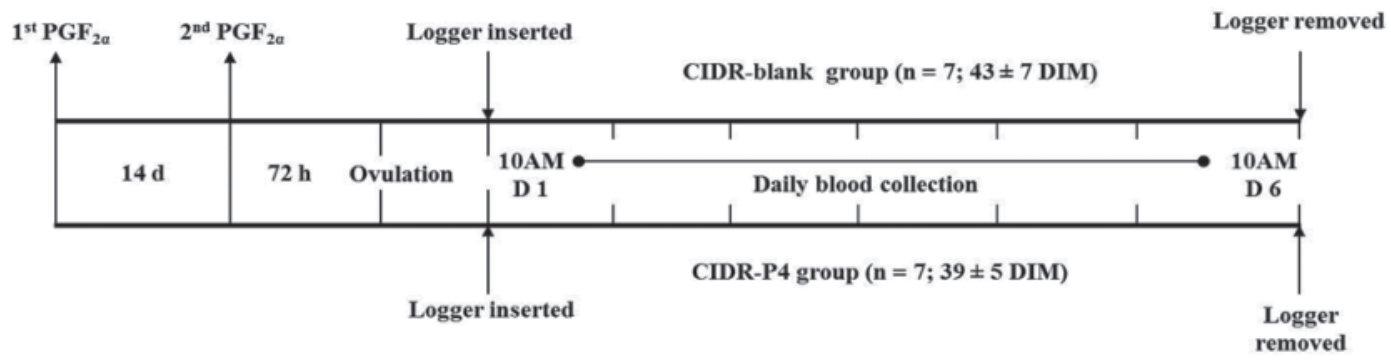

Experiment 3

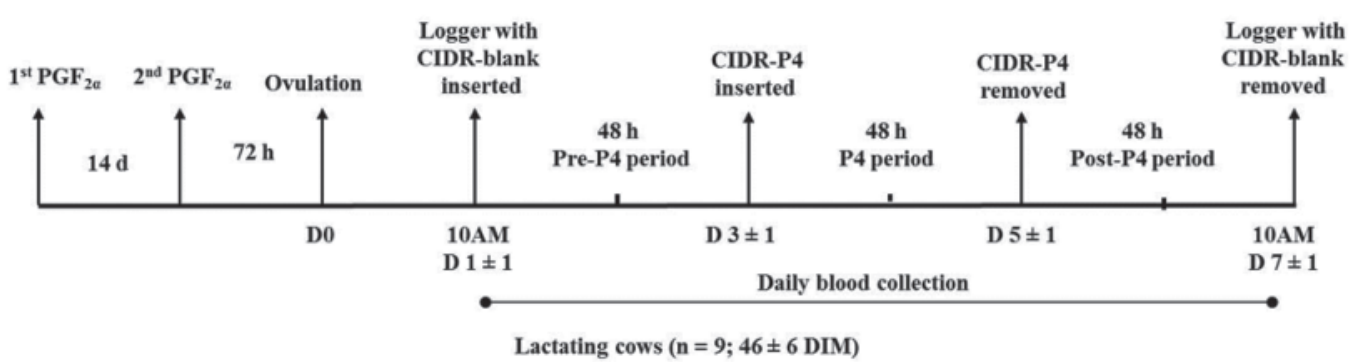

Figure 1. Experimental design considering 3 defined experiments. CIDR $=$ controlled internal drug release $($ CIDR $)$; CIDR-blank $=$ progesterone (P4)-free CIDR; CIDR-P4 = CIDR containing $1.38 \mathrm{~g}$ of P4.

lected when the temperature loggers were inserted and removed, respectively.

\section{Experiment 2}

In this experiment, 14 postpartum healthy, cyclic, lactating, nonpregnant (10 primiparous, 4 multiparous; $41 \pm 6$ DIM) cows were included. Estrous cycles of cows were synchronized by administering 2 injections of $\mathrm{PGF}_{2 \alpha} 14 \mathrm{~d}$ apart. Cows were assigned randomly to 1 of the 2 treatments using a random treatment allocation plan generated using SPSS software (SPSS Inc., Munich, Germany) before the initiation of the trial. Seven cows ( 5 primiparous, 2 multiparous; $43 \pm$ 7 DIM) received a temperature logger attached to a CIDR without P4 (CIDR-blank; Pfizer Animal Health,
Berlin, Germany) $1 \mathrm{~d}$ after confirmed ovulation. In 7 cows (5 primiparous, 2 multiparous; $39 \pm 5$ DIM) a temperature logger was inserted $1 \mathrm{~d}$ after confirmed ovulation using a CIDR (Pfizer Animal Health) containing $1.38 \mathrm{~g}$ P4 (CIDR-P4) as described in Figure 1. The temperature logger was attached to the body of the CIDR-P4 by using 2 latex rubber bands (0.5 $\mathrm{cm}$ wide). Vaginal temperatures were measured for $6 \mathrm{~d}$ consecutively. Blood samples were collected daily (0700 $\pm 1 \mathrm{~h})$.

\section{Experiment 3}

Estrous cycles of 9 lactating, cyclic cows (5 primiparous, 4 multiparous; $46 \pm 6$ DIM) were synchronized with 2 injection of $\mathrm{PGF}_{2 \alpha} 14 \mathrm{~d}$ apart. The day of ovula- 
tion was considered $\mathrm{d} 0$. Cows were enrolled $1 \pm 1 \mathrm{~d}$ after confirmed ovulation and received a temperature logger attached to a CIDR-blank. Two days later (i.e., d $3 \pm 1$ ), a CIDR-P4 was inserted on top of the CIDRblank. On d $5 \pm 1$ and $\mathrm{d} 7 \pm 1$, respectively, the CIDRP4 and CIDR-blank attached to the temperature logger were removed (Figure 1). Vaginal temperatures were measured for $6 \mathrm{~d}$ consecutively. Blood samples were collected daily $(0700 \pm 1 \mathrm{~h})$. Relative to the insertion of the temperature logger attached to a CIDR-blank and the CIDR-P4, three 48-h intervals were defined: pre-treatment (d 1 and $\mathrm{d} 2$ ), P4 treatment (d 3 and $\mathrm{d}$ 4 ), and post-treatment (d 5 and d 6).

\section{Statistical Analyses}

Data from temperature and temperature-humidity index (THI) loggers were downloaded into Excel spreadsheets (Office 2003, Microsoft Deutschland GmbH, Munich, Germany) and analyzed using SPSS for Windows (version 19.0, SPSS Inc.). Vaginal temperature values below $37.5^{\circ} \mathrm{C}$ were considered artifacts due to confounding by ambient temperature after logger movements and excluded from the analysis.

Hourly ambient temperature and relative humidity means were produced by averaging 2 measures recorded. Temperature-humidity index was calculated according to Kendall et al. (2008): THI $=(1.8 \times$ ambient temperature; $\left.{ }^{\circ} \mathrm{C}+32\right)-[(0.55-0.0055 \times$ relative humidity; \% $) \times\left(1.8 \times\right.$ ambient temperature; $\left.{ }^{\circ} \mathrm{C}-26\right)$ ]. Hourly vaginal temperature means were produced for each cow by averaging 6 measures and paired with the corresponding rectal temperature. The relationship between rectal and vaginal temperature was assessed using the paired $t$-test and the Pearson correlation for each of the 3 experiments. Pearson correlation method was used to study the effect of serum P4 on rectal and vaginal temperature, respectively.

Effects of ambient temperature, relative humidity, and THI on rectal and vaginal temperatures, respectively, were evaluated with the Pearson correlation method for the 3 experiments, separately. In all 3 experiments, the effect of parity on rectal and vaginal temperature was evaluated and confirmed negligible.

In experiment 1, differences between BT (rectal and vaginal temperatures) and $\mathrm{P} 4$ concentration of pregnant and nonpregnant, lactating cows were analyzed as a repeated-measure ANOVA using a linear mixed model procedure in SPSS. The effect of time of day and the day of the experiment ( $\mathrm{n}=7 \mathrm{~d}$ ) and their interactions with BT (rectal and vaginal temperature) and serum P4 concentration were included in the model. The scaled identity structure was used, because it resulted in the model with the lowest Akaike information criterion value. Mean differences of rectal and vaginal temperatures and serum P4 in the pregnant and nonpregnant cows was quantified with least significant difference (LSD) post hoc test.

In experiment 2, effects of 2 treatments (i.e., CIDRblank and P4), time of day (i.e., $24 \mathrm{~h}$ ), day of experiment $(\mathrm{n}=6 \mathrm{~d})$, hour of experiment $(\mathrm{n}=144 \mathrm{~h})$, and their interactions with BT (rectal and vaginal temperatures) and serum P4 concentration of cows were evaluated as a repeated-measure ANOVA using a linear mixed model procedure in SPSS. The scaled identity structure was used, because it resulted in the model with the lowest Akaike information criterion value. Mean difference of rectal and vaginal temperatures and serum P4 in the pregnant and nonpregnant cows was tested with LSD post hoc test.

In experiment 3 , the effect of exogenous $\mathrm{P} 4$ concentration on vaginal and rectal temperatures and $\mathrm{P} 4$ was assessed comparing the 3 defined periods (i.e., pre-P4, P4, and post-P4 treatment) as a repeated-measure ANOVA using a linear mixed model procedure in SPSS. The scaled identity structure was used, because it resulted in the model with the lowest Akaike information criterion value. The effect of time of day, day of experiment $(\mathrm{n}=6 \mathrm{~d}$ ), and their interactions with BT (rectal and vaginal temperature) were included in the model. Mean difference of rectal and vaginal temperatures and serum $\mathrm{P} 4$ concentration between the 3 periods was tested with LSD post hoc test. The THI was considered a covariate in experiments to quantify its effect.

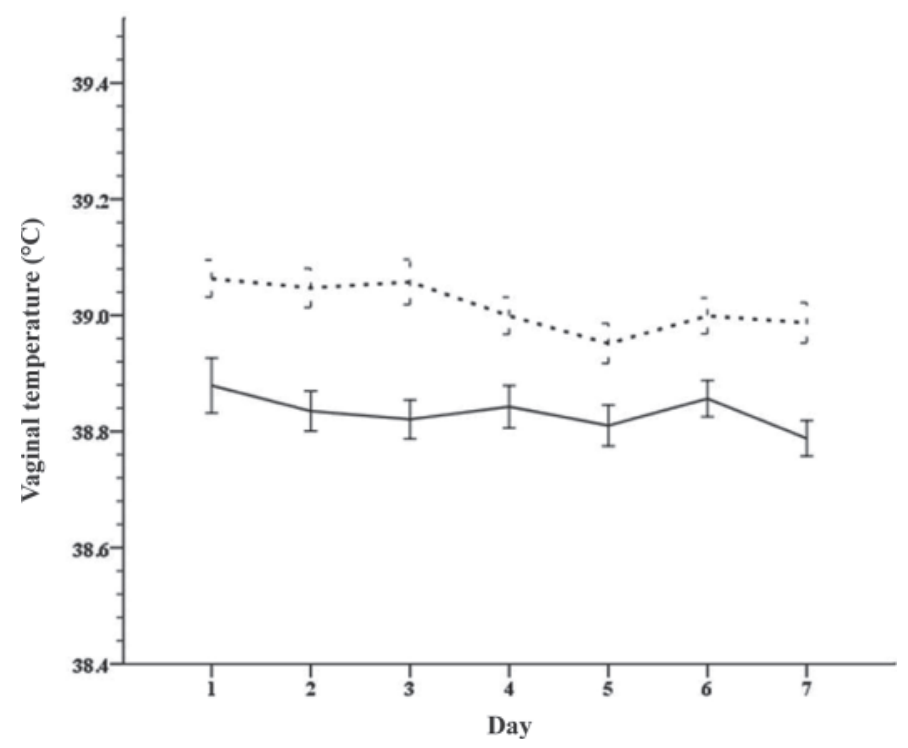

Figure 2. Daily hourly vaginal temperature (mean $\pm \mathrm{SD}$ ) of lactating, nonpregnant (solid line; $\mathrm{n}=9$ ) and lactating, pregnant cows (dotted line; $\mathrm{n}=9$ ) in experiment 1. 
Table 1. Relationships (coefficient of correlation) of ambient temperature, relative humidity, temperature-humidity index, and vaginal temperature of lactating, nonpregnant $(\mathrm{n}=9)$ and pregnant cows $(\mathrm{n}=9)$ of experiment 1

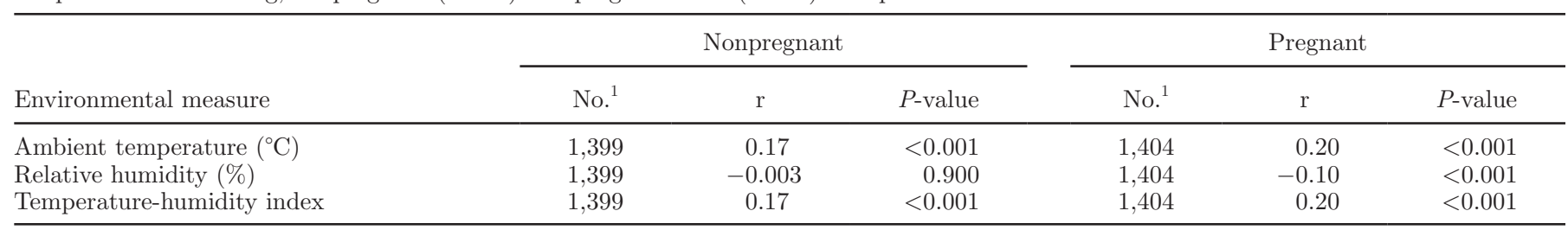

${ }^{1}$ Number of paired observations.

The post hoc compute archive power analyses were performed in G*Power 3 software (http://www.psycho. uni-duesseldorf.de/abteilungen/aap/gpower3/download-and-register) to quantify magnitude of treatment effect on vaginal temperature in the 3 experiments. The post hoc repeated-measure ANOVA between factor power analyses model was used including $20 \%$ of accepting null hypothesis in error (Araujo and Frøyland, 2007; Prajapati et al., 2010) for all experiments. The post hoc effect size (f) and power of analyses $(1-\beta)$ were evaluated and interpreted according to Cohen (1988) and Prajapati et al. (2010).

\section{RESULTS}

\section{Experiment 1}

One nonpregnant and 1 pregnant cow were excluded because the serum $\mathrm{P} 4$ concentration did not meet the inclusion criteria and for fever of unknown origin, respectively. In total, 16,848 (10-min) vaginal temperature observations were recorded. After excluding $0.2 \%$ $(\mathrm{n}=30)$ artifacts, 2,803 $(\mathrm{n}=1,404$ nonpregnant cows; $\mathrm{n}=1,399$ pregnant cows) hourly vaginal temperature means were used for both groups.

For the 7-d study period, the ambient temperatures and THI $( \pm \mathrm{SD})$ were $15.0 \pm 0.4^{\circ} \mathrm{C}$ and $58.8 \pm 4.5$, respectively. Ambient temperature and THI were correlated with vaginal temperature $(P<0.001$; Table 1$)$ but not with rectal temperature $(P>0.05)$. The effect of THI as a covariate was nonexistent $(P=0.485)$ and excluded from the analysis.
Vaginal temperatures were greater $\left(0.3 \pm 0.01^{\circ} \mathrm{C}\right)$ in pregnant cows than in nonpregnant cows $(P=0.007$; Table 2 and Figure 2). The vaginal temperature of both groups demonstrated an effect of time of day $(P$ $<0.001)$ and an effect of the 7 experimental days $(P$ $<0.001$ ). Furthermore, vaginal temperature of both groups demonstrated an interaction with time of day $(P<0.001)$ and the 7 experimental days $(P=0.001)$. Both pregnant and nonpregnant cows demonstrated a daily vaginal temperature rhythm. In pregnant cows, this rhythm occurred with a greater magnitude of change $(P<0.001$; Figure 3$)$. Rectal temperatures of nonpregnant and pregnant cows did not differ $(P=$ 0.106 ) and we observed no effect of the 7 experimental days $(P=0.1)$. An effect of time of day was observed for both nonpregnant and pregnant cows $(P=0.001)$. In both groups, rectal temperature was $0.2 \pm 0.04^{\circ} \mathrm{C}$ greater at $1700 \pm 1 \mathrm{~h}$ than at $0700 \pm 1 \mathrm{~h}(P=0.001)$.

We observed a relationship between rectal and vaginal temperatures for nonpregnant cows ( $\mathrm{n}=126$ paired observations; $\mathrm{r}=0.71 ; P<0.001)$ and pregnant cows ( $\mathrm{n}=126$ paired observations; $\mathrm{r}=0.84 ; P<0.001)$, respectively. Vaginal temperature was greater than rectal temperature in both groups (nonpregnant cows: $0.2 \pm$ $0.1^{\circ} \mathrm{C}$; pregnant cows: $\left.0.2 \pm 0.05^{\circ} \mathrm{C} ; P<0.001\right)$.

Serum P4 concentrations of pregnant cows were greater than those of nonpregnant cows, both at insertion $(7.4 \pm 1.6$ vs. $0.3 \pm 0.2 \mathrm{ng} / \mathrm{mL} ; P<0.001)$ and removal $(6.5 \pm 1.2$ vs. $2.5 \pm 1.2 \mathrm{ng} / \mathrm{mL} ; P<0.001)$ of the temperature loggers. In nonpregnant cows, serum $\mathrm{P} 4$ concentration was greater on $\mathrm{d} 7(2.5 \pm 1.2 \mathrm{ng} / \mathrm{mL})$ than on d $1(0.3 \pm 0.2 \mathrm{ng} / \mathrm{mL} ; P<0.001)$. In nonpreg-

Table 2. Hourly vaginal and rectal temperatures (mean \pm SD) of lactating, nonpregnant and pregnant cows of experiment $1^{1}$

\begin{tabular}{|c|c|c|c|c|c|}
\hline \multirow[b]{2}{*}{ Status } & \multirow{2}{*}{$\begin{array}{l}\text { Cows } \\
\text { (no.) }\end{array}$} & \multicolumn{2}{|c|}{ Vaginal temperature } & \multicolumn{2}{|c|}{ Rectal temperature } \\
\hline & & No. ${ }^{2}$ & ${ }^{\circ} \mathrm{C}$ & $\mathrm{No}^{2}$ & ${ }^{\circ} \mathrm{C}$ \\
\hline Lactating, nonpregnant & 9 & 1,399 & $38.8 \pm 0.3^{\mathrm{a}}$ & 126 & $38.5 \pm 0.5^{\circ}$ \\
\hline Lactating, pregnant & 9 & 1,404 & $39.1 \pm 0.4^{\mathrm{b}}$ & 126 & $38.7 \pm 0.3^{\circ}$ \\
\hline
\end{tabular}




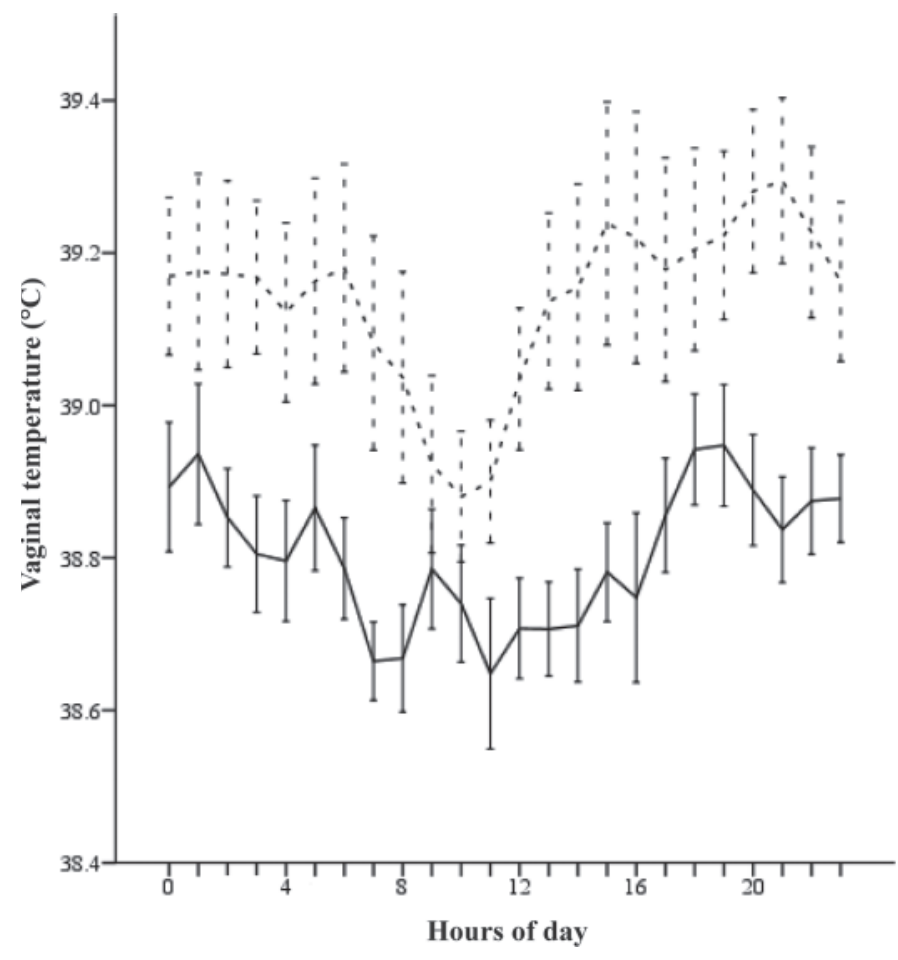

Figure 3. Average daily vaginal temperature (mean \pm SD) rhythm of lactating, nonpregnant (solid line; $\mathrm{n}=9$ ) and lactating, pregnant cows (dotted line; $\mathrm{n}=9$ ) in experiment 1 .

nant cows, serum P4 concentration increased $(2.1 \pm 0.4$ $\mathrm{ng} / \mathrm{mL}$ ) during the $5 \mathrm{~d}$ between insertion and removal of the temperature logger $(\mathrm{n}=6$ paired observations; $P<0.001)$. In pregnant cows, no difference in serum $\mathrm{P} 4$ concentrations was observed during the $5 \mathrm{~d}$ between insertion and removal of the temperature logger $(P=$ $0.17)$.

The effect size and power of analysis based on vaginal temperature observations and cow numbers of the 2 groups $(\mathrm{n}=9)$ were 0.8 and 0.88 , respectively.

\section{Experiment 2}

All 14 cows met the inclusion criteria. In total, 11,736 (10-min) vaginal temperature observations were recorded. After excluding $4.1 \%(\mathrm{n}=486)$ temperature values $<37.5^{\circ} \mathrm{C}, 1,875$ hourly means of vaginal temperature were calculated $(\mathrm{n}=875$, CIDR-blank; $\mathrm{n}=1,000$; CIDR-P4).

For the 6-d study period, the ambient temperatures and THI were $12.7 \pm 2.0^{\circ} \mathrm{C}$ and $55.2 \pm 3.0$, respectively. A relationship between ambient temperature, relative humidity, THI, and BT did not exist $(P>0.05)$.

Vaginal temperature of CIDR-P4 cows $\left(39.0 \pm 0.2^{\circ} \mathrm{C}\right)$ did not differ from that of CIDR-blank cows $(38.9 \pm$ $\left.0.2^{\circ} \mathrm{C} ; P=0.58\right)$. Effects of time of day $(P<0.001)$, day of experiment $(P<0.001 ;$ Figure 4$)$, and hour of experiment $(P<0.001)$ were observed on vaginal temperatures of both treatments. An interaction of the $6 \mathrm{~d}$ with vaginal temperature of both treatments was observed $(P<0.001$; Figure 4$)$. We observed no interaction between time of day and vaginal temperature for both treatments $(P=0.481)$. Vaginal temperature was negligibly $\left(0.04\right.$ to $\left.0.07^{\circ} \mathrm{C}\right)$ lower in the CIDR-blanktreated control cows on d 1 compared with the other days (i.e., d 2 to $6 ; P<0.05$ ). The 6 -d average of vaginal temperature of CIDR-blank-treated cows was $38.9 \pm 0.2^{\circ} \mathrm{C}$. For the CIDR-P4-treated cows, vaginal temperatures differed between the $6 \mathrm{~d}(P<0.01)$. On d 3 after inserting the CIDR-P4, vaginal temperature reached a maximum $\left(39.2 \pm 0.4^{\circ} \mathrm{C} ; P<0.01\right)$ compared with the remaining days. Average vaginal temperature was $0.3^{\circ} \mathrm{C}$ greater on $\mathrm{d} 3$ than on $\mathrm{d} 1(P<0.001)$ and $\mathrm{d} 5(P<0.001)$. Rectal temperatures were similar between the 2 treatments $(P=0.1)$. No effect of the 6 experimental days $(P=0.4)$ was observed in CIDR-P4 or CIDR-blank cows. An effect of time of day was observed on CIDR-P4 and CIDR-blank cows $(P=0.001)$. Both treatments demonstrated a greater $\left(0.2 \pm 0.03^{\circ} \mathrm{C}\right)$ rectal temperature at $1700 \pm 1 \mathrm{~h}$ than at $0700 \pm 1 \mathrm{~h}$ $(P=0.001)$.

A correlation existed between rectal and vaginal temperatures in the CIDR-blank control group $(\mathrm{n}=$ 60 paired observations; $\mathrm{r}=0.57 ; P<0.001$ ) and the

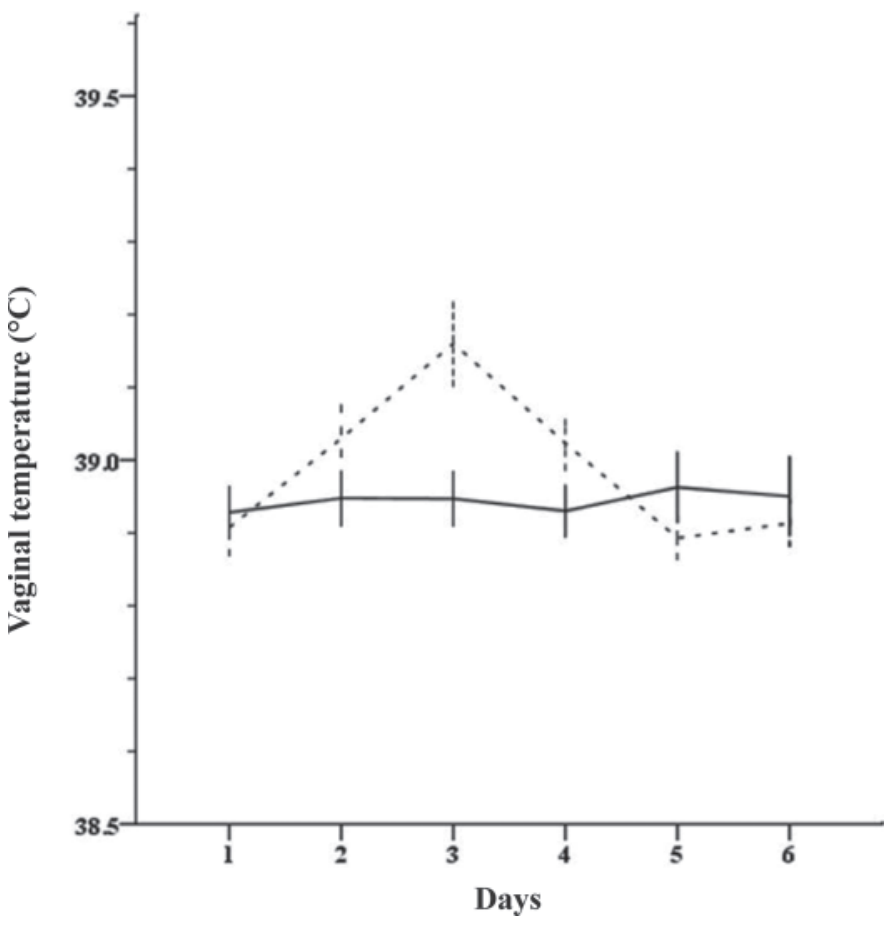

Figure 4. Vaginal temperature (mean $\pm \mathrm{SD}$ ) of control cows (solid line; $\mathrm{n}=7$ ) and progesterone-treated cows (dotted line; $\mathrm{n}=7$ ) in experiment 2 . 


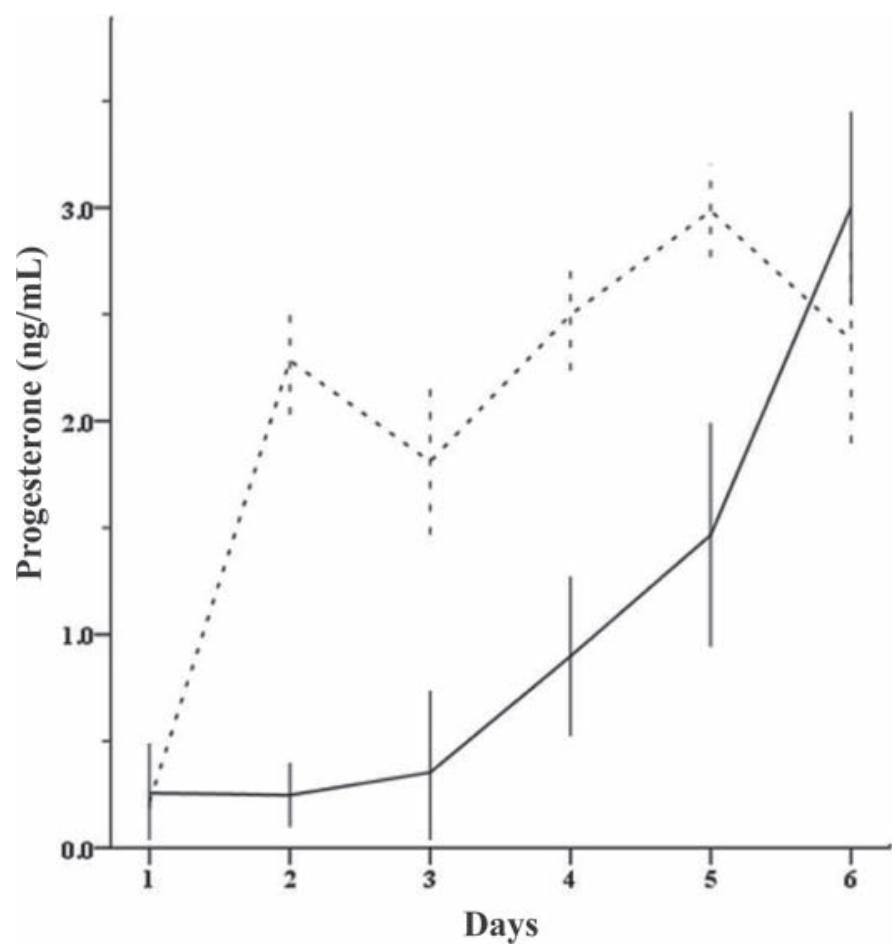

Figure 5. Serum progesterone concentration (mean $\pm \mathrm{SD}$ ) of control cows (solid line; $\mathrm{n}=7$ ) and progesterone-treated cows (dotted line; $\mathrm{n}=7$ ) in experiment 2 .

CIDR-P4 group $(\mathrm{n}=62$ paired observations; $\mathrm{r}=0.59$; $P<0.001)$. Vaginal temperature was greater than rectal temperature in both treatments (CIDR-blank: $0.2 \pm$ $0.2^{\circ} \mathrm{C}$; CIDR-P4: $\left.0.2 \pm 0.1^{\circ} \mathrm{C} ; P<0.001\right)$.

Serum P4 concentrations of CIDR-blank or CIDR-P4 cows were not associated with vaginal temperatures. Serum P4 concentrations of CIDR-blank cows were $0.8 \mathrm{ng} / \mathrm{mL}$ lower than those of CIDR-P4 treated cows $(P<0.001)$. The day of experiment had an effect on serum $\mathrm{P} 4$ concentrations of both treatment groups $(P$ $<0.001)$ and an interaction $(P<0.001)$ was found. Serum P4 concentration of CIDR-P4 cows was greater than that of CIDR-blank cows on d $2(P<0.001)$, d 3 $(P<0.001)$, d $4(P<0.001)$, and d $5(P<0.001)$ (Fig- ure 5). Serum P4 concentrations did not differ between CIDR-blank and CIDR-P4 cows on $\mathrm{d} 1(P=0.1)$ or $\mathrm{d}$ $6(P=0.94)$.

The effect size and power of analysis based on vaginal temperature observations and cow numbers of the 2 groups $(\mathrm{n}=7)$ were 0.3 and 0.8 , respectively.

\section{Experiment 3}

All 9 cows met the inclusion criteria. In total, 6,560 (10-min) vaginal temperature observations were recorded. After excluding 3.6\% $(\mathrm{n}=242)$ temperature measures $<37.5^{\circ} \mathrm{C}, 1,054$ hourly vaginal temperature means were calculated. During the 6-d study period, ambient temperature and THI were $13.0 \pm 2.1^{\circ} \mathrm{C}$ and $55.9 \pm 3.2$, respectively. A relationship between ambient temperature, relative humidity, THI, and BT did not exist $(P>0.05)$.

Vaginal temperatures differed among the 3 periods $(P=0.009)$. Vaginal temperature was $0.2^{\circ} \mathrm{C}$ and $0.1^{\circ} \mathrm{C}$ greater during the $\mathrm{P} 4$ treatment period than during the pre-P4 treatment $(P=0.005)$ or post-P 4 treatment periods $(P=0.002)$, respectively (Table 3$)$. In addition, we observed an effect of the 6 experimental days $(P<0.001)$ and time of day $(P<0.001)$ on vaginal temperature of the 9 cows. We detected no interaction of treatment by period $(P=0.595)$, but did observe an interaction of treatment by time of day $(P=0.04)$. Rectal temperatures were not different between the 3 periods $(P=0.326$; Table 3$)$. No effects of the 6 experimental days $(P=0.215)$ and time of day $(P=$ $0.319)$ were observed. Rectal and vaginal temperatures were correlated $(\mathrm{n}=90 ; \mathrm{r}=0.73 ; P<0.001)$; vaginal temperature was $0.2 \pm 0.05^{\circ} \mathrm{C}$ greater than rectal temperature $(P<0.001)$.

Serum P4 concentrations of the CIDR-P4 treatment $(P<0.001)$ and post-P4 treatment period $(P=0.001)$ were greater than that of the pre-P4 treatment period. No difference was noted between serum P4 concentrations of the CIDR-P4 treatment and post-P4 treatment period $(P=0.363$; Table 3$)$. As in experiment 2 , serum

Table 3. Vaginal and rectal temperatures and serum progesterone concentration (mean \pm SD) of 9 lactating, nonpregnant cows during 3 defined periods relative to progesterone treatment of experiment $3^{1}$

\begin{tabular}{|c|c|c|c|c|c|c|c|}
\hline Period & Cows (no.) & \multicolumn{2}{|c|}{ Vaginal temperature } & \multicolumn{2}{|c|}{ Rectal temperature } & \multicolumn{2}{|c|}{ Progesterone } \\
\hline Pre-treatment & 9 & 264 & $38.9 \pm 0.3^{\mathrm{a}}$ & 21 & $38.7 \pm 0.3^{\mathrm{a}}$ & 18 & $0.2 \pm 0.2^{\mathrm{a}}$ \\
\hline Post-treatment & 9 & 391 & $39.0 \pm 0.2^{\mathrm{c}}$ & 36 & $38.8 \pm 0.3^{\mathrm{a}}$ & 18 & $2.3 \pm 0.7^{\mathrm{b}}$ \\
\hline
\end{tabular}

${ }^{\mathrm{a}-\mathrm{c}}$ Means within a column with different superscripts differ $(P<0.05)$.

${ }^{1}$ Mean and SD were calculated from all measures recorded in the 3 periods.

${ }^{2}$ Number of measurements. 
$\mathrm{P} 4$ concentration was not associated with vaginal temperature. The effect size and power of analysis based on vaginal temperature observations and cow numbers of the 3 periods were 0.2 and 0.8 , respectively.

\section{DISCUSSION}

Our experiments substantiate the effect of endogenous and exogenous $\mathrm{P} 4$ on vaginal temperature in dairy cows. Fluctuations in BT are well known during the estrous cycle, pregnancy, and parturition (Wrenn et al., 1961; Lammoglia et al., 1997; Kyle et al., 1998). Only one study demonstrated a thermogenic effect of P4 on BT in ovariectomized dairy cows (Wrenn et al., 1959). To our knowledge, the current study is the first to demonstrate an effect of endogenous and exogenous $\mathrm{P} 4$ on vaginal temperature in ovary-intact dairy cows.

Relevant relationships were not observed between ambient temperature or THI and BT during the 3 experiments. The absence of an association between ambient temperature and BT is indicative of relatively moderate environment conditions compared with other studies conducted in tropical climates (Kendall et al., 2006).

In our experiments, the Pearson correlation between rectal and vaginal temperature varied from $\mathrm{r}=0.59$ to 0.73 in nonpregnant cows and was $r=0.84$ in pregnant cows. These coefficients of correlation are in the range of previous studies conducted in peak lactation cows $(\mathrm{r}=0.46)$, healthy postpartum cows $(\mathrm{r}=0.81)$, and sick postpartum cows $(\mathrm{r}=0.76)$ (Bewley et al., 2008; Vickers et al., 2010). Variation in measured values can be caused by multiple factors of either method, such as intra-observer variability, penetration depth, or logger movement (Burfeind et al., 2010; Vickers et al., 2010).

The effect size of all 3 experiments on the basis of vaginal temperature observations was within the range of the scale demonstrated by Cohen (1988) and Prajapati et al. (2010). The power analysis $(1-\beta)$ for the 3 experiments suggested that the chance of error $(\beta)$ in accepting the null hypothesis was $0.2(20 \%)$ for experiments 2 and 3 and 0.11 (11\%) for experiment 1.

Not surprisingly, serum P4 concentrations were greater in pregnant cows than in nonpregnant cows in experiment 1. At the same time, pregnant cows had greater vaginal temperature than nonpregnant cows (Table 2 and Figure 2). These data support Wrenn et al. (1961), who reported that BT was greatest in the last trimester of pregnancy. The authors concluded that increased BT during pregnancy is a result of continued $\mathrm{P} 4$ secretion during gestation from the CL and the placenta. Future investigations are needed to validate this vaginal temperature increase and to evaluate potential practical applications in dairy cows.
Considering the greater vaginal temperature in pregnant cows in experiment 1 , the effect of $\mathrm{P} 4$ was further studied with 2 different approaches (experiments 2 and 3 ) by supplementing $1.38 \mathrm{~g}$ of $\mathrm{P} 4$ via a CIDR.

In experiment 2 , the effect of exogenous $\mathrm{P} 4$ on $\mathrm{BT}$ was evaluated during the first $6 \mathrm{~d}$ after ovulation by comparing CIDR-P4 ( $\mathrm{n}=7)$ and CIDR-blank cows (n $=7$ ). After insertion of a CIDR-P4 on $\mathrm{d} 1$ following confirmed ovulation, vaginal temperature increased on $\mathrm{d} 2$, peaked on $\mathrm{d} 3$, and persisted on $\mathrm{d} 4$. The peak in vaginal temperature on d 3 occurred $24 \mathrm{~h}$ later compared with that in the study conducted by Wrenn et al. (1959), who reported a maximum increase in vaginal temperature on d 2 after injecting $250 \mathrm{mg}$ of $\mathrm{P} 4$. In this study, the interval between insertion of the CIDR-P4 and vaginal temperature increase was $36 \pm 4 \mathrm{~h}$, which is longer than that of Wrenn et al. (1959), who reported a 12- to 18-h lag period after s.c. P4 injection. The delayed increase of vaginal temperature in our study might be due to the different route of $\mathrm{P} 4$ administration (CIDR vs. s.c. injection). Serum P4 concentration increased faster in $\mathrm{P} 4$-treated cows compared with CIDR-blank control cows. In the CIDR-blank control cows, serum P4 concentration increased above $1 \mathrm{ng} / \mathrm{mL}$ after $\mathrm{d} 4$ due to the growing CL. This supports an earlier study that reported a peak in serum P4 concentration $24 \mathrm{~h}$ after inserting a CIDR-P4 in 4 ovariectomized cows (Long et al., 2009).

In experiment 3 , the effect of exogenous $\mathrm{P} 4$ treatment on BT was evaluated by conducting a within-cow comparison in 9 lactating, nonpregnant cows considering 3 defined periods. The increase in vaginal temperature during the $\mathrm{P} 4$ treatment period compared with the pre-treatment period coincided with the increase in serum $\mathrm{P} 4$ concentration. Although vaginal temperature decreased $\left(0.1^{\circ} \mathrm{C}\right)$ during the post-treatment period, this decrease had no diagnostic significance. Furthermore, when the CIDR-P4 was removed, P4 remained elevated during the post-treatment period (Table 3). Most likely, this finding was due to the $\mathrm{P} 4$ secretion from the growing CL, which had been demonstrated by the untreated control cows of experiment 2 after $\mathrm{d}$ 4. Vaginal temperature decreased by $0.2^{\circ} \mathrm{C}$ during the post-treatment period. The reason for this decrease in vaginal temperature during the post-treatment period remains speculative.

Our group recently demonstrated a higher BT $\left(\geq 0.1^{\circ} \mathrm{C}\right)$ during the luteal phase in dairy cows (Suthar et al., 2011) but observed no direct correlation between BT and P4 concentration. With the present experiments conducted in pregnant and nonpregnant cows after the administration of exogenous $\mathrm{P} 4$, this finding could be confirmed. These data provide evidence that $\mathrm{P} 4$ per se is not directly related to BT. 


\section{CONCLUSIONS}

Vaginal temperature was greater in cows with elevated P4 concentrations due to pregnancy or P4 supplementation. A direct correlation between serum P4 concentrations and BT, however, did not exist. Further investigations are warranted to better understand the pathways of the thermogenic effect of $\mathrm{P} 4$ on $\mathrm{BT}$.

\section{ACKNOWLEDGMENTS}

The authors gratefully appreciate the cooperation with the owners, the herdswoman, and the staff of the dairy farm. We acknowledge J. S. Patel (Department of Agricultural Statistics, Anand Agricultural University, India), who helped us in analyzing data. This project was funded by Tiergyn Berlin e.V. (Berlin, Germany) We acknowledge the financial support given to Vishal Suthar by the European Commission under Erasmus Mundus External Cooperation Window Lot 15 for conducting this work as part of his $\mathrm{PhD}$ dissertation.

\section{REFERENCES}

Ambrose, D. J., D. G. V. Emmanuel, M. G. Colazo, and J. P. Kastelic. 2008. Short communication: Pregnancy rates to timed artificial insemination in Holstein heifers given prostaglandin $\mathrm{F}_{2 \alpha}$ twentyfour hours before or concurrent with removal of an intravaginal progesterone-releasing insert. J. Dairy Sci. 91:2678-2683.

Araujo, P., and L. Frøyland. 2007. Statistical power and analytical quantification. J. Chromatogr. B Analyt. Technol. Biomed. Life Sci. 847:305-308.

Bewley, J. M., M. E. Einstein, M. W. Grott, and M. M. Schutz. 2008. Comparison of reticular and rectal core body temperatures in lactating dairy cows. J. Dairy Sci. 91:4661-4672.

Birgel, E. H. Jr., E. Grunert, and J. A. Soares. 1994. The preliminary stage of labor in cattle in relation to the clinical signs of labor and the course of progesterone secretion for the prediction of the calving time. Dtsch. Tierarztl. Wochenschr. 101:355-359.

Burfeind, O., and W. Heuwieser. 2011. Validity of prepartum temperature changes to predict parturition in dairy cows. Reprod. Domest. Anim. 46(Suppl. 1):10.

Burfeind, O., M. A. G. von Keyserlingk, D. M. Weary, D. M. Veira, and W. Heuwieser. 2010. Short communication: Repeatability of measures of rectal temperature in dairy cows. J. Dairy Sci. 93:624-627.

Burfeind, O., V. S. Suthar, R. Voigtsberger, S. Bonk, and W. Heuwieser. 2011. Validity of prepartum changes in vaginal and rectal temperature to predict calving in dairy cows. J. Dairy Sci. 94:5053-5061. http://dx.doi.org/10.3168/jds.2011-4484.

Cohen, J. 1988. Statistical Power Analysis for the Behavioral Sciences. L. Erlbaum Associates, Hillsdale, NJ.
Cooper-Prado, M. J., N. M. Long, E. C. Wright, C. L. Goad, and R. P. Wettemann. 2011. Relationship of ruminal temperature with parturition and estrus of beef cows. J. Anim. Sci. 89:1020-1027.

Kendall, P. E., P. P. Nielsen, J. R. Webster, G. A. Verkerk, R. P. Littlejohn, and L. R. Matthews. 2006. The effects of providing shade to lactating dairy cows in a temperate climate. Livest. Sci. 103:148-157.

Kendall, P. E., C. B. Tucker, D. E. Dalley, D. A. Clark, and J. R. Webster. 2008. Milking frequency affects the circadian body temperature rhythm in dairy cows. Livest. Sci. 117:130-138.

Kendall, P. E., and J. R. Webster. 2009. Season and physiological status affects the circadian body temperature rhythm of dairy cows. Livest. Sci. 125:155-160.

Kornmatitsuk, B., K. K. Önigsson, H. Kindahl, H. Gustafsson, M. Forsberg, and A. Madej. 2000. Clinical signs and hormonal changes in dairy heifers after induction of parturition with prostaglandin $\mathrm{F}_{2 \alpha}$. J. Vet. Med. A Physiol. Pathol. Clin. Med. 47:395-409.

Kyle, B. L., A. D. Kennedy, and J. A. Small. 1998. Measurement of vaginal temperature by radiotelemetry for the prediction of estrus in beef cows. Theriogenology 49:1437-1449.

Lammoglia, M. A., R. A. Bellows, R. E. Short, S. E. Bellows, E. G. Bighorn, J. S. Stevenson, and R. D. Randel. 1997. Body temperature and endocrine interactions before and after calving in beef cows. J. Anim. Sci. 75:2526-2534.

Larson, J. E., G. C. Lamb, J. S. Stevenson, S. K. Johnson, M. L. Day, T. W. Geary, D. J. Kesler, J. M. DeJarnette, F. N. Schrick, A. DiCostanzo, and J. D. Arseneau. 2006. Synchronization of estrus in suckled beef cows for detected estrus and artificial insemination and timed artificial insemination using gonadotropin-releasing hormone, prostaglandin $\mathrm{F}_{2 \alpha}$, and progesterone. J. Anim. Sci. 84:332-342.

Long, S. T., C. Yoshida, and T. Nakao. 2009. Plasma progesterone profile in ovariectomized beef cows after Intra-vaginal insertion of new, once-used or twice-used CIDR. Reprod. Domest. Anim. 44:80-82.

Prajapati, B., M. Dunne, and R. Armstrong. 2010. Sample size estimation and statistical power analyses. Optometry Today 16. Accessed Jul. 20, 2011. http://www.optometry.co.uk/uploads/ articles/statistical\%20article.pdf.

Suthar, V. S., O. Burfeind, J. S. Patel, A. J. Dhami, and W. Heuwieser. 2011. Body temperature rhythm around induced estrus in dairy cows. J. Dairy Sci. 94:2368-2373.

Vickers, L. A., O. Burfeind, M. A. G. von Keyserlingk, D. M. Veira, D. M. Weary, and W. Heuwieser. 2010. Technical note: Comparison of rectal and vaginal temperatures in lactating dairy cows. J. Dairy Sci. 93:5246-5251.

von Krueger, X., and W. Heuwieser. 2011. Effects of CIDR on 4-day service rate, pregnancy rate and vaginal irritation in dairy heifers. Tierärz. Praxis. Großtiere. 39:277-280.

Wrenn, T. R., J. Bitman, and J. F. Sykes. 1959. The thermogenic influence of progesterone in ovariectomized cows. Endocrinology $65: 317-321$.

Wrenn, T. R., J. Bitman, and J. F. Sykes. 1958. Body temperature variations in dairy cattle during the estrous cycle and pregnancy. J. Dairy Sci. 41:1071-1076.

Wrenn, T. R., J. Bitman, and J. F. Sykes. 1961. Diurnal patterns of bovine body temperature. J. Dairy Sci. 44:2077-2080. 